\title{
Equipment to prevent, diagnose, and treat hypothermia: a survey of Norwegian pre-hospital services
}

\author{
Anders M Karlsen, Øyvind Thomassen*, Bjarne H Vikenes and Guttorm Brattebø
}

\begin{abstract}
Introduction: Hypothermia is associated with increased morbidity and mortality in trauma patients and poses a challenge in pre-hospital treatment. The aim of this study was to identify equipment to prevent, diagnose, and treat hypothermia in Norwegian pre-hospital services.

Method: In the period of April-August 2011, we conducted a survey of 42 respondents representing a total of 543 pre-hospital units, which included all the national ground ambulance services, the fixed wing and helicopter air ambulance service, and the national search and rescue service. The survey explored available insulation materials, active warming devices, and the presence of protocols describing wrapping methods, temperature monitoring, and the use of warm i.v. fluids.

Results: Throughout the services, hospital duvets, cotton blankets and plastic "bubble-wrap" were the most common insulation materials. Active warming devices were to a small degree available in vehicle ambulances (14\%) and the fixed wing ambulance service (44\%) but were more common in the helicopter services (58-70\%). Suitable thermometers for diagnosing hypothermia were lacking in the vehicle ambulance services (12\%). Protocols describing how to insulate patients were present for $73 \%$ of vehicle ambulances and $70 \%$ of Search and Rescue helicopters. The minority of Helicopter Emergency Medical Services (42\%) and Fixed Wing (22\%) units was reported to have such protocols.
\end{abstract}

Conclusion: The most common equipment types to treat and prevent hypothermia in Norwegian pre-hospital services are duvets, plastic "bubble wrap", and cotton blankets. Active external heating devices and suitable thermometers are not available in most vehicle ambulance units.

\section{Introduction}

Accidental hypothermia represents a challenge in the pre-hospital setting during all seasons and is identified as an independent risk factor for increased mortality and morbidity in trauma patients [1-4]. Trauma patients lose temperature at the accident site, during transport, and in the emergency department $[5,6]$. The definition of hypothermia is usually a core temperature below $35^{\circ} \mathrm{C}$, but there is a considerable individual difference at what temperature the clinical effects occur [7].

Data are limited on the incidence of hypothermia in Scandinavian trauma patients. Studies from the United States and Australia show an incidence of hypothermia

\footnotetext{
* Correspondence: oyvind.thomassen2@helse-bergen.no

Department of Anaesthesia \& intensive care, Haukeland University hospital, N-5021 Bergen, Norway
}

\section{Biomed Central}

in trauma patients from 1.6 to $15.7 \%[1-3,8]$. The risk of hypothermia increases with injury severity and has been reported to occur in over $40 \%$ of trauma patients presenting signs of hypoperfusion [9].

Knowledge concerning current treatment practices and use of equipment among rescue personnel for treating and preventing hypothermia outside hospitals is limited and warrants further investigation. One retrospective study of military personnel found that despite introduction of new wrapping concepts and active heating equipment, wool blanket was the most used utility [10]. A survey of American mountain rescue teams found that most teams preferred active warming during evacuation, with chemical heat packs as the dominant method [11]. A survey of EMS personnel in one region in Norway found that wool blankets and hot iv fluids were the most preferred 
interventions among rescue personnel with hypothermic patients [12].

The aim of this study was to identify equipment available for diagnosis, prevention, and treatment of hypothermia in Norwegian pre-hospital services, defined as the ground ambulance service (AS), helicopter emergency medical service (HEMS), fixed wing air ambulance service $(\mathrm{FW})$, and the national search and rescue service (SAR).

\section{Methods}

The AS is operated through 18 health trusts and conducted approximately 600,000 missions in 2010 , serving a population of 4.9 million. The number of ground ambulances was estimated to be around 490 units in daily operation during the study period. HEMS consisted of twelve physicianstaffed ambulance helicopters operating from eleven bases, FW of nine planes assigned to seven bases, and SAR had ten helicopters assigned to six bases. Other organisations that handle patients outside the hospital (primary care, non-governmental organisations like the Red Cross, alpine rescue teams, and ski patrols) also provide initial treatment but were not included in this study.

Structured telephone interviews were performed in the period of April-August 2011 and were guided by a questionnaire on the following topics: available insulation materials, active warming equipment, protocols on how to insulate patients, hypothermia thermometers and preferred anatomical measuring sites, pre-warmed i.v. fluids, and infusion heating devices (questionnaire available from corresponding author.). A hypothermia thermometer was defined as a thermometer designed to measure temperature below $32^{\circ} \mathrm{C}$. Optional equipment not stored in the units and equipment designed for incubators were excluded. The study was approved by the regional research ethics committee.

In the AS, the primary contact was the head of each health trust's ambulance department who either responded personally or referred to personnel with better knowledge of the current status. The respondents had to have knowledge of organisational structure and guidelines and detailed knowledge of the current equipment setup in their service. All respondents were asked if there was an equal equipment setup for the whole area and to report the number of ambulance units in their service. In cases of reported variation in equipment setup, a questionnaire was to be distributed electronically to all local station managers in the area. Respondents in the three aero-medical services (FW, HEMS, and SAR) consisted of one of the medical crew members on call.

Data were entered into a standardised database and analysed in a spreadsheet (Microsoft Excel 2010, Microsoft Corp, Redmond, WA, US). Ambiguous answers were interpreted in consensus among the authors, and respondent confirmations were sought when needed.

\section{Results}

We achieved a $100 \%$ response rate, with a total of 42 respondents (Table 1). All AS representatives answered that equipment was uniform for all units in their area, and no follow-up at a lower level was needed to complete data.

The dominant insulation materials throughout the services were hospital duvets, plastic "bubble-wrap" and cotton blankets. Wool blankets, "space blankets", and separate head covers were less frequently reported. Insulation equipment such as insulated shelters and similar insulation materials were absent from most services, with the exception of the SAR services. All SAR bases reported having an insulated shelter bag intended for patient use (Fjellduken', Jerven as. Odda, Norway). $28 \%$ of all AS units had other specially designed insulation products (Table 2).

$18(43 \%)$ of the respondents reported having equipment for providing active warming, which was available in most HEMS (58\%) and SAR service units (70\%), but to a lesser degree in the FW (44\%) and AS (14\%) units. Heating pads were most frequent, followed by hot water bottles and heating blankets.

Protocols describing how to insulate patients were present for $73 \%$ of AS and 70\% of SAR units. The minority of HEMS (42\%) and FW (22\%) units was reported to have such protocols.

All air services reported having hypothermia thermometers, in contrast to the AS in which $12 \%$ of the units had them. The reported anatomical measuring sites were rectal, oesophageal, and tympanic.

Hot i.v. fluids were available in all SAR units and the majority of AS (91\%) and HEMS services (92\%) but in only one of the FW bases (11\%). Infusion warmers were available to a small number of the units (0-20\%).

\section{Discussion}

The $100 \%$ response rate makes this survey a valid overview of the equipment to prevent, diagnose, and treat hypothermia in the Norwegian pre-hospital services.

The insulation material was largely similar within the SAR and FW services, while greater regional differences

\section{Table 1 Respondents}

\begin{tabular}{lcc}
\hline Services & $\begin{array}{c}\text { Number of } \\
\text { respondents }\end{array}$ & $\begin{array}{c}\text { Total number of } \\
\text { units represented } \\
\text { by respondents }\end{array}$ \\
\hline Ambulance services & 18 & 512 \\
Fixed wing air ambulance & 7 & 9 \\
Helicopter air ambulance & 11 & 12 \\
Rescue service & 6 & 10 \\
Total & $\mathbf{4 2}$ & $\mathbf{5 4 3}$ \\
\hline
\end{tabular}


Table 2 Equipment to prevent, diagnose and treat hypothermia in Norway

\begin{tabular}{|c|c|c|c|c|}
\hline & $\begin{array}{c}\text { Ground ambulance } \\
\text { services (AS) } \\
\text { Total } 512 \\
\text { n and (\%) }\end{array}$ & $\begin{array}{c}\text { Fixed wing } \\
(\mathrm{FW})(\mathrm{n}=9) \\
\text { Total } 9 \\
\mathrm{n} \text { and }(\%)\end{array}$ & $\begin{array}{c}\text { Helicopter emergency } \\
\text { medical service(HEMS) } \\
\text { Total } 12 \\
\mathrm{n} \text { and (\%) }\end{array}$ & $\begin{array}{c}\text { National search and } \\
\text { rescue service (SAR) } \\
\text { Total } 10 \\
\text { n and }(\%)\end{array}$ \\
\hline \multicolumn{5}{|l|}{ Insulation material available } \\
\hline Space blankets & $151(29)$ & $5(56)$ & $8(67)$ & 0 \\
\hline Hospital duvets & $468(91)$ & $9(100)$ & $11(92)$ & $10(100)$ \\
\hline Cotton blankets & $436(85)$ & $7(78)$ & $7(58)$ & $2(20)$ \\
\hline Plastic "bubble wrap" & $428(84)$ & 0 & $12(100)$ & $10(100)$ \\
\hline Wool blankets & $154(30)$ & $9(100)$ & $2(17)$ & $9(90)$ \\
\hline Sleeping bags & 0 & 0 & 0 & 0 \\
\hline Shelter bags (not insulated) & 0 & 0 & 0 & 0 \\
\hline Insulated shelter bags & 0 & 0 & $2(17)$ & $10(100)$ \\
\hline Separate head cover & $220(43)$ & 0 & $7(58)$ & $10(100)$ \\
\hline Body bags & $512(100)$ & 0 & 0 & $10(100)$ \\
\hline Plastic covers & 0 & $1(11)$ & 0 & 0 \\
\hline Other ${ }^{\mathrm{a}}$ & $148(29)$ & 0 & 0 & 0 \\
\hline Active warming equipment & $72(14)$ & $4(44)$ & $7(58)$ & $7(70)$ \\
\hline Chemical heat pads & $57(11)$ & $4(44)$ & $7(58)$ & $5(50)$ \\
\hline Water bottles & 0 & 0 & 0 & $5(50)$ \\
\hline Electrical heating blankets & 0 & 0 & $4(33)$ & 0 \\
\hline Forced air warmer & 0 & 0 & $2(17)$ & 0 \\
\hline Warm i.v. fluid protocol & $15(3)$ & 0 & 0 & 0 \\
\hline Other & 0 & 0 & 0 & 0 \\
\hline Treatment protocols & $373(73)$ & $2(22)$ & $5(42)$ & $7(70)$ \\
\hline \multicolumn{5}{|l|}{ Hypothermia thermometers } \\
\hline Yes & $61(12)$ & $7(100)$ & $12(100)$ & $10(100)$ \\
\hline Not sure & $123(24)$ & 0 & 0 & 0 \\
\hline For rectal use & $61(100)^{b}$ & $7(100)$ & $12(100)$ & $8(80)$ \\
\hline For oesophageal use & 0 & $7(100)$ & $12(100)$ & $8(80)$ \\
\hline For tympanic use & $46(75)^{\mathrm{b}}$ & 0 & 0 & $2(20)$ \\
\hline For oral use & $0(0)^{b}$ & $1(11)$ & 0 & 0 \\
\hline For axillary use & $0(0)^{b}$ & $3(33)$ & 0 & 0 \\
\hline Other $^{d}$ & 0 & $4(44)$ & 0 & $3(30)$ \\
\hline Hot i.v. fluids & $468(91)$ & $1(11)$ & $11(92)^{c}$ & $10(100)$ \\
\hline Infusion heaters & $15(3)$ & 0 & $2(17)$ & $2(20)$ \\
\hline
\end{tabular}

${ }^{\mathrm{a}}$ Blizzard ${ }^{\circledast}$ rescue blanket, vacuum mattresses.

${ }^{b}$ Number and percentage of units represented in "Yes" category $(n=61)$.

'HEMS fluids are kept warm in storage lockers at the base, not in the helicopter unit.

dBladder, skin.

emerged within the HEMS and AS. Hospital duvets were present in almost all units. The study also showed that "bubble wrap" were common in all services except FW, which has some insulating effect and also acts as a vapour barrier [13,14].

Active warming equipment was unavailable to most AS units (14\%) but fairly common in FW (44\%), HEMS
(58\%), and SAR (70\%) units. The main heat source in the survey was heat packs. In the Scandinavian countries there are no current consensus regarding which role active warming devices should have in pre-hospital care. In cases of mild to moderate hypothermia in a patient with intact shivering response, the effect of active warming on core temperature have been questioned [15]. The rate of 
re-warming will largely be the same as if heat were not added because shivering effectively re-establishes the temperature balance. The main benefits of active rewarming are in these cases to reduce energy consumption and increase comfort $[15,16]$. In patients with impaired shivering response due to severe hypothermia, injury, disease, intubation or use of drugs, insulation alone may not be sufficient to maintain core temperature and these patients may require active warming $[17,18]$.

Head cover intended for patient use was present in the equipment setup of all SAR bases but to a lesser extent in the other services.

A written procedure describing how to insulate patients who either are hypothermic or in danger of becoming hypothermic was reported by the majority of respondents in the AS (73\%) and SAR (70\%) services. In HEMS and FW, the minority reported having such a protocol $(42 \%, 22 \%$ respectively). The appropriateness of the content and personnel compliance was not included in the study aim and was not assessed. The presence of protocols may be viewed as an indicator of whether or not hypothermia prevention and treatment receives attention.

In addition to clinical signs and environmental clues, a reliable measurement of the core temperature is important in assessing the degree of hypothermia. This study shows that the majority of the AS units lack suitable tools for diagnosing hypothermia. Oesophageal and rectal measurements correspond well with pulmonary artery blood temperature and were the measurement sites reported in the aero-medical services [19]. The ambulance service reported rectal and tympanic temperature as measurement locations. Tympanic measurement without isolation of the ear canal may be inaccurate in the pre-hospital environment, especially if the victim has been submerged [20]. ERC Guidelines 2010 recommend the use of oesophageal, rectal, urinary bladder, or tympanic measurement to determine core temperature in hypothermic patients [21]. A survey of Norwegian rescue workers showed that rectal temperature was the most common measuring site in the vehicle ambulance services, consistent with our findings [12].

Depending on ambient temperature, significant temperature loss occurs in the i.v. tube and infusion bag and is a potential factor for iatrogen heat loss [22-24]. Outside the hospital, it is almost impossible to deliver fluid to patients at near body temperature without specially designed equipment. In most cases, giving intravenous fluids with the intention to re-warm the patient will therefore be counterproductive $[25,26]$. Heated storage cabinets were reported to be available in almost all AS (91\%), HEMS (92\%), and SAR units (100\%). Infusion heaters were reported only in a small number of the services.

\section{Limitations}

This study has several limitations. We achieved a 100\% response to this survey and believe that the data are representative of pre-hospital units in Norway. However, structured interviews are known to suffer from bias. Respondents may provide inaccurate information to give a favourable impression of their service or may remember wrong or misunderstand questions. The interviewer may also unconsciously influence the respondent through his or her behaviour. Equipment is constantly changing, and current status may have changed since the study period.

\section{Conclusion}

The most common equipment types used to treat and prevent hypothermia in Norwegian pre-hospital services are duvets, plastic "bubble wrap", and cotton blankets. Active external heating devices and suitable thermometers were available in only a few of the ground ambulance services. The findings in this survey may reflect a lack of consensus in how to best prevent and treat hypothermia in the prehospital setting. Further research on the effects of the various wrapping concepts is needed.

\section{Competing interests}

The authors declared that they have no competing interests.

\section{Authors' contributions}

All authors have participated in the development of the protocol and the questionnaire. AMK has performed the interviews and provided the first draft of the article. All authors have been active in the revision and approved the final manuscript.

\section{Acknowledgements}

The authors want to thank the respondents who participated in this survey.

Received: 19 April 2013 Accepted: 12 August 2013

Published: 12 August 2013

\section{References}

1. Ireland S, Endacott R, Cameron P, Fitzgerald M, Paul E: The incidence and significance of accidental hypothermia in major trauma-a prospective observational study. Resuscitation 2011, 82(3):300-306.

2. Waibel BH, Schlitzkus LL, Newell MA, Durham CA, Sagraves SG, Rotondo MF: Impact of hypothermia (below 36 degrees C) in the rural trauma patient. J Am Coll Surg 2009, 209(5):580-588.

3. Martin RS, Kilgo PD, Miller PR, Hoth JJ, Meredith JW, Chang MC: Injuryassociated hypothermia: an analysis of the 2004 National Trauma Data Bank. Shock 2005, 24(2):114-118.

4. Jurkovich GJ, Greiser WB, Luterman A, Curreri PW: Hypothermia in trauma victims: an ominous predictor of survival. J Trauma 1987, 27(9):1019-1024.

5. Gregory JS, Flancbaum L, Townsend MC, Cloutier CT, Jonasson O: Incidence and timing of hypothermia in trauma patients undergoing operations. J Trauma 1991, 31(6):795-798. discussion 798-800.

6. Kober A, Scheck T, Fulesdi B, Lieba F, Vlach W, Friedman A, Sessler DI: Effectiveness of resistive heating compared with passive warming in treating hypothermia associated with minor trauma: a randomized trial. Mayo Clin Proc 2001, 76(4):369-375.

7. Soreide K: Clinical and translational aspects of hypothermia in major trauma patients: from pathophysiology to prevention, prognosis and potential preservation. Injury 2013. Epub ahead of print.

8. Shafi S, Elliott AC, Gentilello L: Is hypothermia simply a marker of shock and injury severity or an independent risk factor for mortality in trauma patients? Analysis of a large national trauma registry. J Trauma 2005, 59(5):1081-1085. 
9. Beilman GJ, Blondet JJ, Nelson TR, Nathens AB, Moore FA, Rhee P, Puyana $J C$, Moore EE, Cohn SM: Early hypothermia in severely injured trauma patients is a significant risk factor for multiple organ dysfunction syndrome but not mortality. Ann Surg 2009, 249(5):845-850.

10. Nesbitt MAP: Current practice of thermoregulation during the transport of combat wounded. J Trauma 2010, 69(Suppl 1):S162-167.

11. Hamilton RS, Paton BC: The diagnosis and treatment of hypothermia by mountain rescue teams: a survey. Wilderness Environ Med 1996, 1:28-37.

12. Bjerkaas E, Iversen RA, Gilbert M: Hypotermi og væskebehandling. Master thesis: University of Tromsø; 2002.

13. Thomassen O, Faerevik H, Osteras O, Sunde GA, Zakariassen E, Sandsund M, Heltne JK, Brattebo G: Comparison of three different prehospital wrapping methods for preventing hypothermia-a crossover study in humans. Scand J Trauma Resusc Emerg Med 2011, 19:41.

14. Henriksson O, Lundgren JP, Kuklane K, Holmer I, Bjornstig U: Protection against cold in prehospital care-thermal insulation properties of blankets and rescue bags in different wind conditions. Prehosp Disaster Med 2009, 24(5):408-415.

15. Williams AB, Salmon A, Graham P, Galler D, Payton MJ, Bradley M: Rewarming of healthy volunteers after induced mild hypothermia: a healthy volunteer study. Emerg Med J 2005, 22(3):182-184.

16. Lundgren P, Henriksson O, Naredi P, Bjornstig U: The effect of active warming in prehospital trauma care during road and air ambulance transportation-a clinical randomized trial. Scand I Trauma Resusc Emerg Med 2011, 19:59.

17. Hultzer MV, Xu X, Marrao C, Bristow G, Chochinov A, Giesbrecht GG: Pre-hospital torso-warming modalities for severe hypothermia: a comparative study using a human model. CJEM 2005, 7(6):378-386.

18. Langhelle A, Lockey D, Harris T, Davies G: Body temperature of trauma patients on admission to hospital: a comparison of anaesthetised and non-anaesthetised patients. Emerg Med J 2012, 29(3):239-242.

19. Lefrant JY, Muller L, de La Coussaye JE, Benbabaali M, Lebris C, Zeitoun N, Mari C, Saissi G, Ripart J, Eledjam JJ: Temperature measurement in intensive care patients: comparison of urinary bladder, oesophageal, rectal, axillary, and inguinal methods versus pulmonary artery core method. Intensive Care Med 2003, 29(3):414-418.

20. Rogers IR, Brannigan D, Montgomery A, Khangure N, Williams A, Jacobs I: Tympanic thermometry is unsuitable as a screening tool for hypothermia after open water swimming. Wilderness Environ Med 2007, 18(3):218-221

21. Soar J, Perkins GD, Abbas G, Alfonzo A, Barelli A, Bierens JJ, Brugger H, Deakin $C D$, Dunning J, Georgiou M, et al: European resuscitation council guidelines for resuscitation, section 8: cardiac arrest in special circumstances: electrolyte abnormalities, poisoning, drowning, accidental hypothermia, hyperthermia, asthma, anaphylaxis, cardiac surgery, trauma, pregnancy, electrocution. Resuscitation 2010 2010, 81(10):1400-1433.

22. Faries $G$, Johnston C, Pruitt KM, Plouff RT: Temperature relationship to distance and flow rate of warmed i.v. fluids. Ann Emerg Med 1991, 20(11):1198-1200.

23. Lapostolle F, Sebbah JL, Couvreur J, Koch FX, Savary D, Tazarourte K, Egman G, Mzabi L, Galinski M, Adnet F: Risk factors for onset of hypothermia in trauma victims: the HypoTraum study. Crit Care 2012, 16(4):R142.

24. Handrigan MT, Wright RO, Becker BM, Linakis JG, Jay GD: Factors and methodology in achieving ideal delivery temperatures for intravenous and lavage fluid in hypothermia. Am J Emerg Med 1997, 15(4):350-353.

25. Paal $\mathrm{P}$, Beikircher $\mathrm{W}$, Brugger $\mathrm{H}$ : Avalanche emergencies: review of the current situation. Anaesthesist 2006, 55(3):314-324.

26. Watts DD, Roche M, Tricarico R, Poole F, Brown JJ Jr, Colson GB, Trask AL, Fakhry SM: The utility of traditional prehospital interventions in maintaining thermostasis. Prehosp Emerg Care 1999, 3(2):115-122.

doi:10.1186/1757-7241-21-63

Cite this article as: Karlsen et al:: Equipment to prevent, diagnose, and treat hypothermia: a survey of Norwegian pre-hospital services.

Scandinavian Journal of Trauma, Resuscitation and Emergency Medicine $201321: 63$

\section{Submit your next manuscript to BioMed Central and take full advantage of:}

- Convenient online submission

- Thorough peer review

- No space constraints or color figure charges

- Immediate publication on acceptance

- Inclusion in PubMed, CAS, Scopus and Google Scholar

- Research which is freely available for redistribution

Submit your manuscript at www.biomedcentral.com/submit 